\title{
ANIBACTERIAL EFFICACY AND GAS CHROMATOGRAPHY-MASS SPECTROMETERY ANALYSIS OF BIOACTIVE COMPOUNDS PRESENT IN DIFFERENT EXTRACTS OF ALLIUM SATIVUM
}

\author{
DUSHYANT SHARMA, REENA RANI, MONIKA CHATURVEDI, JAYA PARKASH YADAV*
}

Department of Genetics, Maharshi Dayanand University, Rohtak-124001, Haryana, India. Email: yadav1964@rediffmail.com

Received: 01 December 2017, Revised and Accepted: 10 January 2018

\section{ABSTRACT}

Objective: Medicinal plants are rich libraries containing wide variety of compounds of therapeutic values. Allium sativum commonly known as garlic is a very well-known medicinal plants being used with food products. In the present study, the antibacterial activity of different extracts of A. sativum was investigated along with their phytochemical analysis by gas chromatography-mass spectrometery (GC-MS) to explore antimicrobial compounds present in extracts.

Methods: The antibacterial activity of A. sativum was evaluated against 9 reference bacterial strains and 3 MDR bacterial strains including Escherichia coli MDREC1, Klebsiella pneumoniae MDRKP2, and Pseudomonas aeruginosa MDRPA3 by microbroth dilution and agar well diffusion method.

Results: The results obtained from agar well diffusion assay showed the zone of inhibition from 12 to $26 \mathrm{~mm}$ for different extracts. The methanol and acetone extracts were found most potent against reference and MDR bacterial strains. MIC values were in the range of 1.87-7.5 mg/ml. Further, GCMS analysis confirmed the presence of 35 compounds including dodecanoic acid, hexadecanoic acid, and methyl ester in common.

Conclusion: The varied antimicrobial activity of extracts was due to the presence of different concentrations of the identified compounds which can be isolated and used for the treatment of various infectious diseases caused by MDR strains of E. coli, P. aeruginosa, and K. pneumoniae.

Keywords: Antibacterial activity, Allium sativum, Gas chromatography-mass spectrometery, Bioactive compound, MDR Bacterial strains.

(c) 2018 The Authors. Published by Innovare Academic Sciences Pvt Ltd. This is an open access article under the CC BY license (http://creativecommons. org/licenses/by/4. 0/) DOI: http://dx.doi.org/10.22159/ajpcr.2018.v11i4.24053

\section{INTRODUCTION}

Microbial infections are the main cause of morbidity and mortality in developed as well as developing countries, even though a large number of antimicrobial compounds are available for the treatment and management of these diseases. Overexploitation and indiscriminate use of the antibiotics can lead to the development of drug resistance and it is one of the major health problems [1]. Thus, there is an urgent need of the natural products which can be used for the treatment of various infectious diseases.

Plants serve as a source of various effective and powerful drugs right from the time of human civilization. The herbal medicine has a long history in the treatment of several diseases and has been widely spread all around the world [2]. The plant products have played a significant role in the history of drug discovery [3]. It is belief that natural substances have fewer side effects than synthetic pharmaceuticals and are easily available from the surroundings [4]. Herbal medicines are in great demand both in developed and developing countries for primary health care. Today also, many rural areas of developing countries are depend on traditional medicine for their primary health care [5]. India is one of the oldest, richest, and most diverse culturals traditionally associated with the use of medicinal plants [6].

Alliaceae is an important medicinal plant family and the genus Allium has over 700 members with special tastes, forms, and colors [7]. Species in the Alliaceae family are perennial herbs. The leaves grow from a bulb at the base of the plant. The leaves vary from flat to circular in crosssection and may be hollow, with parallel veins running lengthwise along the blade. The family was formerly included in a broadly defined Liliaceae. Plants of this family are widely distributed in temperate, tropical, and semiarid regions. Common examples of this family are onion, garlic, and chives.
Allium sativum is a species of Allium commonly known as garlic, which is being used as a spicy flavoring agent in food as well as folk medicine across the globe since centuries [8]. A. sativum is a hardy, bulbous, perennial plant, $1.2 \mathrm{~m}$ in height native to Mediterranean regions of Africa and Europe. The most commonly used part of A. sativum is its bulb. This plant contains carbohydrates, reducing sugars, lipids, flavonoids, ketones, alkaloids, steroids, and triterpenes [9]. It is a remarkable plant, reported to have various pharmacological activities such as antimicrobial, antithrombotic, hypolipidemic, antiarthritic, hypoglycemic, and antitumor activity [10,11]. The characteristic pungent smell of garlic is due to the presence of allicin which is also responsible for the antibacterial activity. Many of the health benefits associated with garlic consumption have been attributed to the thiosulfinates, the most abundant class of organosulfur compounds, found in freshly chopped or crushed garlic. Oil-macerated heated garlic products contained mainly vinyldithiins, ajoene, and small amount of sulfides $[12,13]$

Keeping these aspects in view, the efforts were made for better understanding of qualitative, quantitative chemical composition by gas chromatography-mass spectroscopy (GC-MS) analysis and to explore the antibacterial activity of organic solvent extracts of A. sativum.

\section{METHODS}

Preparation of plant extracts

Garlic (A. sativum) bulbs were purchased from the local market of Rohtak $\left(28.8909^{\circ} \mathrm{N}\right.$ and $\left.76.5796^{\circ} \mathrm{E}\right)$, Haryana, India. The bulbs were peeled off, followed by washing and subjected to shade dry. The dried material was grinded in electrical grinder to obtain powder form. Six organic solvents, i.e. methanol, acetone, chloroform, ethyl acetate, petroleum ether, and benzene were used for extraction in 1:10 ratio by cold percolation for 48-72 h (50 g dried powder). The obtained extracts were filtered using Whatman No. 1 filter paper and then concentrated 
using rotatory evaporator at $40^{\circ} \mathrm{C}$. The total yield of the extracts was measured and \% age of extracted value was calculated by the following formula: Quantity of extract obtained× 100/weight of initial quantity of dried extract.

\section{Antibacterial activity}

The antibacterial assay was carried out using agar well diffusion against 9 reference strains, namely, (1) Shigella flexneri ATCC 12022, (2) Enterococcus faecalis ATCC 29212, (3) Staphylococcus aureus ATCC 259323, (4) Proteus mirabilis ATCC 43071, (5) Salmonella typhi ATCC 13311, (6) Serratia marcescens ATCC 27137, (7) Klebsiella pneumoniae ATCC 700603, (8) Escherichia coli ATCC 25922, and (9) Pseudomonas aeruginosa ATCC 27853 and three MDR bacterial strains, namely, (1) E. coli MDREC1, (2) K. pneumoniae MDRKP2, and (3) P. aeruginosa MDRPA3 [14]. A sterile wire-loop was used to pick up the isolated colonies of tested bacteria and to emulsify into $10 \mathrm{ml}$ of peptone water solution. Turbidity of the suspension of test organism was compared with McFarland turbidity standard. Using a sterile swab stick, the test organisms were spreaded on autoclaved solidified nutrient agar media. The inoculated plates were then allowed to solidify. The wells were made using borer of $6 \mathrm{~mm}$ diameter. In each well, from a stock solution of $100 \mathrm{mg} / \mathrm{ml}$, the $20,40,60$, and $80 \mu \mathrm{l}$ of plant extracts were poured. The Petri plates were wrapped with parafilm to avoid the environmental contamination and incubated at $37^{\circ} \mathrm{C}$ for $24 \mathrm{~h}$. Streptomycin discs of $10 \mu \mathrm{g}$ (HiMedia Laboratories Pvt. Ltd. India) were used as a positive control and diluted dimethyl sulfoxide (DMSO) was used as a negative control. After incubation, the plates were examined for zones of inhibitions. The zones of inhibition were measured in $\mathrm{mm}$ using a plastic ruler HiAntibiotic ZoneScaleTM-C (HiMedia Laboratories Pvt. Ltd., India). All the experiments were performed in triplicates, and their mean and standard deviation was calculated for further statistical analysis using MS Excel program.

\section{Minimum inhibitory concentration (MIC)}

MIC is the lowest concentration of an antimicrobial compound able to inhibit the observable growth of a microorganism after overnight incubation. MIC for different extracts against different tested bacterial strains was determined in 96 multi-well microtiter plates using the method of Sarker et al. with slight modifications, and the plates were prepared in triplicate and incubated at $37^{\circ} \mathrm{C}$ for $18-24 \mathrm{~h}$ [15]. The resazurin dye was used as indicator and color changes from purple to pink or to colorless indicated growth of microbes. The lowest concentration at which no color change occurred was recorded as the MIC value of that extract. The streptomycin was taken as a positive control and diluted DMSO was taken as a negative control for antimicrobial susceptibility test of extracts.

\section{GCMS analysis}

Phytochemical analysis of all six extracts of A. sativum was carried out using GCMS analyzer (BRUKER SCION 436-GC SQ). Extracts were dissolved in methanol (high-performance liquid chromatography grade) and filtered through Whatman ${ }^{\mathrm{TM}}$ FILTER DEVICE $(0.2 \mu \mathrm{m})$. Helium (99.99\%) was used as carrier gas, at a flow rate of $1 \mathrm{ml} / \mathrm{min}$ in split mode. RESTEK Rtx ${ }^{\circledR}-5$ (Crossbond ${ }^{\circledR} 5 \%$ diphenyl/95\% dimethyl polysiloxane) with $30 \mathrm{~m}$ length, $0.25 \mu \mathrm{m} \mathrm{df}$, and $0.25 \mathrm{~mm}$ ID column was used for separation of phytochemicals. $2 \mu \mathrm{L}$ of sample was injected to column. The injector temperature was $280^{\circ} \mathrm{C}$. The temperature of oven starts at $70^{\circ} \mathrm{C}$ and hold for $2 \mathrm{~min}$, and then, it was raised at a rate of $7^{\circ} \mathrm{C}$ per minute up to $320^{\circ} \mathrm{C}$, hold for $1 \mathrm{~min}$. Temperature of ion sources was maintained at $250^{\circ} \mathrm{C}$. The mass spectrum was obtained by electron ionization at $70 \mathrm{eV}$ and detector operates in scan mode 30-500 Da atomic units. Total running time was 38.71 min including 3 min solvent delay.

\section{RESULTS}

\section{Yield of extracts}

The total yield of extracts is shown in Table 1. Maximum yield $13.70 \%$ was obtained in methanol extract.

\section{Antibacterial activity}

Antibacterial activity of extracts of $A$. sativum was investigated against nine reference bacterial strains and 3 MDR bacterial strains at different concentrations by agar well diffusion assay. Results obtained in agar well diffusion assay are shown in Table 2 . All extracts except benzene showed considerable antibacterial activity with the diameter of inhibition zones ranging from 10 to $26 \mathrm{~mm}$ against different bacteria used in the study. Methanol and acetone extracts of A. sativum exhibited antibacterial activity against wide range of bacterial strains based on the study included MDR strains of E. coli, P. aeruginosa, and K. pneumoniae. However, methanol extract showed higher antibacterial activity as compared to other extracts. Methanol extract of A. sativum showed concentration-dependent activity. The highest dose of $8 \mathrm{mg} / \mathrm{ml}$ was found to be most effective. Highest zones of inhibition were reported of 26 and $23 \mathrm{~mm}$ against $S$. flexneri and S. marcescens, respectively. Similarly, acetone extract showed 24 and $22 \mathrm{~mm}$ zone of inhibition against $S$. flexneri and $S$. marcescens, respectively. In case of MDR strains, the acetone extract was reported to have the highest activity against E. coli MDREC1 and K. pneumonia MDRKP2 with 24 and $20 \mathrm{~mm}$ zone of inhibition, respectively, while methanol extract was reported to have the highest activity against $P$. aeruginosa MDRPA3 with a zone of inhibition of $17 \mathrm{~mm}$.

\section{MIC}

MIC values of different extract for tested bacteria have been shown in Table 3. Outcomes of the study showed that MIC values of $A$. sativm extracts were found to be in a range of $1.87 \mathrm{mg} / \mathrm{ml}$ to $7.50 \mathrm{mg} / \mathrm{ml}$. A good correlation of antibacterial activity in agar well diffusion assay and microbroth dilution has been observed. It was found that methanol extract inhibited the total growth total growth of $S$. flexneri at a concentration of $1.87 \mathrm{mg} / \mathrm{ml}$ that is well correlated to agar well diffusion assay where is formed a largest zone of inhibition.

In case of MDR strains, acetone extract was found to have better activity as compared to other extract. MIC values of acetone extracts were to be in the range of $1.87-3.75 \mathrm{mg} / \mathrm{ml}$ that is well correlated with the results of agar well diffusion assay.

\section{GCMS analysis}

A total number of 35 organic compounds were identified by comparing the GCMS spectra result with the NIST MS library. The list of compounds identified from different extracts, i.e. methanol, acetone, ethyl acetate, chloroform, petroleum ether, and benzene is given in Table 4 . The major compounds identified by matching the spectra with NIST library were dodecanoic acid, hexadecanoic acid, methyl ester, di (2-ethylhexyl) adipate, 9-dodecanoic acid-methyl ester, and methyl stearate. The spectra of the GCMS are given in Figs. 1-6.

\section{DISCUSSION}

The rising population is the reason to worry about various health problems due to which the production of natural antimicrobial drugs is being used to control the various infectious diseases. Medicinal plants and spices are generally used natural antimicrobial agents in foods and have been used conventionally for thousands of years by many cultures for controlling common health problems. The secondary metabolites isolated from the plants have gained very high importance due to their effectiveness against multidrug-resistant microbes.

Table 1: Yield of extracts and \% age of extracted values in different solvents

\begin{tabular}{lll}
\hline Solvents & Yield of extracts $\mathbf{( g )}$ & \%age of extracted value \\
\hline Methanol & 6.85 & 13.70 \\
Acetone & 5.0 & 10 \\
Ethyl acetate & 3.30 & 6.6 \\
Chloroform & 1.28 & 2.56 \\
Benzene & 0.925 & 1.85 \\
Petroleum ether & 1.20 & 2.4 \\
\hline
\end{tabular}


A. sativum is traditionally being used as dietary and anti-infective agent [16]. Several in vitro studies support its antibacterial, antifungal, and antiviral properties $[17,18]$. The antimicrobial activity of garlic has been reported due to the presence of phenolic and organosulfur compounds.

It is believed that the secondary metabolite of plants, i.e., tannins, saponins, phenolic compounds, essential oils, and flavonoids is responsible for their bioactive potential [19]. The crude extracts from several plants have been reported for their antibacterial activity against MDR bacterial strains where modern antibiotic therapies have many side effects. In this study, in vitro efficacy of A. sativum extracts on reference strains and MDR strains of bacteria organisms have been analyzed. The agar well diffusion assay is a practical approach to study the efficacy of compounds against bacteria, and by measuring the size of inhibition zone, it is not an adequate method because zone of inhibition might be affected by the solubility, volatization, and rate of diffusion in agar medium or its volatilization, and thus, the results could be affected. Hence, other methods to evaluate antibacterial activity of extracts should be used parallel as the microbroth dilution method confirms this in the present study with a good correlation.

In the previous study, the antibacterial activity was evaluated of ethanol extract of $A$. sativum against MDR clinical isolates of $E$. coli, Enterobacter sp., P. aeruginosa, Proteus sp., Klebsiella sp., S. aureus, and Bacillus sp. and the inhibition zone reported was 18.50,13.50, 19.45, $13.65,11.50,14.55$, and $16.55 \mathrm{~mm}$, respectively [20]. In the present study, the antibacterial activity of methanol extract of $A$. sativum was maximum against reference bacterial strains $S$. flexneri, E. faecalis, and $S$. marcescens with the inhibition zone of 26,22 , and $23 \mathrm{~mm}$, respectively, while in case of MDR strains, the acetone extract was found most active against MDR E. coli MDREC1 and MDR K. pneumonia MDRKP2 with the inhibition zone of 24 and $20 \mathrm{~mm}$, respectively. This higher zone of inhibition may be due to the climatic and geographical conditions from where the plant has been collected and the used concentration in that study was $200 \mu \mathrm{g} / \mathrm{ml}$. The methanolic extract of A. sativum also shows good activity against the MDR strain of $P$. aeruginosa MDRPA3 with inhibition zone of $17 \mathrm{~mm}$.

It has been reported that ethanol and aqueous extracts of $A$. sativum showed antibacterial activity against methicillin-resistant $S$. aureus and penicillin-susceptible $S$. aureus strains with the MIC value of $2 \mathrm{mg} / \mathrm{ml}$, while in case of in vivo study, the extracts of garlic do not inhibit or kill the bacteria significantly [21]. In our study also, the methanol, acetone, chloroform, and petroleum ether extracts of A. sativum show the inhibition of $S$. aureus with the inhibition zone of $17,13,12$, and $12 \mathrm{~mm}$, respectively, but MIC value of these extracts was $7.5 \mathrm{mg} / \mathrm{ml}$ which is higher than the above study which may be due to the use of pepton water medium in spite of Muller-Hinton broth.

Rath and Padhy tested a total of 26 Indian spices against nine MDR bacterial strains which infects urinary tract and $A$. sativum was found active against 6 bacterial strains, namely, S. aureus, Acinetobacter baumannii, Citrobacter freundii, Enterobacter aerogenes, K. pneumoniae, and P. mirabilis, with the inhibition zone of $17,17,18,22,17$, and 21 , respectively, and inactive against remaining three bacterial strain, namely, E. faecalis, E. coli, and $P$. aeruginosa which is contradictory to this study as the methanol and acetone extracts of A. sativum showed good activity against E. coli and P. aeruginosa which may be due to the difference in solvent used for extraction and the methods used for the analysis of antibacterial activity [22].

Many phytochemical analysis studies have been carried out on A. sativum and the different classes of compounds reported in these studies were

Table 2: Zone of inhibition ( $\mathrm{mm}$ ) of different extracts of $A$. sativum against reference and MDR bacterial strains

\begin{tabular}{|c|c|c|c|c|c|c|c|}
\hline Bacterial strain & Methanol & Acetone & Ethyl acetate & Chloroform & Petroleum ether & Benzene & Streptomycin $(10 \mu \mathrm{g}$ disc $)$ \\
\hline S. flexneri & $26 \pm 0.76^{*}$ & $24 \pm 1.00$ & $15 \pm 0.57$ & - & $16 \pm 0.57$ & - & $24 \pm 0.57$ \\
\hline E. feacalis & $22 \pm 0.57$ & $20 \pm 1.00$ & $12 \pm 0.76$ & - & - & - & $24 \pm 0.57$ \\
\hline S. aureus & $17 \pm 0.76$ & $13 \pm 0.76$ & - & $12 \pm 0.57$ & $12 \pm 1.00$ & - & $23 \pm 0.76$ \\
\hline P. mirabilis & $16 \pm 0.57$ & $10 \pm 1.00$ & $19 \pm 1.00$ & $10 \pm 0.76$ & - & - & $23 \pm 1.00$ \\
\hline S. typhi & $14 \pm 1.00$ & $15 \pm 0.57$ & - & - & $15 \pm 1.00$ & - & $20 \pm 1.00$ \\
\hline S. marcescens & $23 \pm 0.76$ & $22 \pm 0.76$ & $20 \pm 1.00$ & - & $18 \pm 0.76$ & - & $20 \pm 0.57$ \\
\hline K. pneumoniae & $19 \pm 0.76$ & $20 \pm 0.57$ & $20 \pm 1.00$ & $15 \pm 1.00$ & - & - & $19 \pm 0.57$ \\
\hline P. aeruginosa & $20 \pm 0.57$ & $17 \pm 1.00$ & $15 \pm 0.57$ & - & $12 \pm 1.00$ & - & $25 \pm 0.76$ \\
\hline E. coli MDREC1 & $15 \pm 0.76$ & $24 \pm 1.00$ & $15 \pm 0.57$ & - & $16 \pm 0.57$ & - & $20 \pm 0.57$ \\
\hline K. pneumoniae MDRKP2 & $16 \pm 0.57$ & $20 \pm 1.00$ & $12 \pm 0.76$ & - & - & - & $19 \pm 0.57$ \\
\hline P. aeruginosa MDRPA3 & $17 \pm 0.76$ & $13 \pm 0.57$ & - & $12 \pm 1.00$ & $12 \pm 1.00$ & - & $20 \pm 0.76$ \\
\hline
\end{tabular}

*The zone of inhibition showed as mean \pm standard deviation (n=3), S. flexneri: Shigella flexneri, E. faecalis: Enterococcus faecalis, S. aureus:

Staphylococcus aureus, P. mirabilis: Proteus mirabilis, S. typhi: Salmonella typhi, S. marcescens: Serratia marcescens, P. aeruginosa: Pseudomonas aeruginosa, K. pneumonia Klebsiella pneumonia, E. coli: Escherichia coli

Table 3: MIC values (mg) of different extracts of $A$. sativum against different reference bacterial strains and MDR strains

\begin{tabular}{|c|c|c|c|c|c|c|}
\hline Bacterial strain & Methanol & Acetone & Ethyl acetate & Chloroform & Petroleum ether & Benzene \\
\hline S. flexneri & 1.87 & 1.87 & 7.5 & - & 3.75 & - \\
\hline E. feacalis & 1.87 & 3.75 & 7.5 & - & - & - \\
\hline S. aureus & 7.5 & 7.5 & - & 7.5 & 7.5 & - \\
\hline P. mirabilis & 7.5 & 7.5 & 3.75 & 7.5 & - & - \\
\hline S. typhi & 7.5 & 7.5 & & - & 7.5 & - \\
\hline S. marcescens & 3.75 & 3.75 & 1.87 & - & 3.75 & - \\
\hline K. pneumoniae & 3.75 & 3.75 & 1.87 & 3.75 & - & - \\
\hline P. aeruginosa & 3.75 & 7.5 & 3.75 & - & 7.5 & - \\
\hline E. coli MDREC1 & 7.5 & 1.87 & 3.75 & - & 3.75 & - \\
\hline K. pneumoniae MDRKP2 & 3.75 & 1.87 & 7.5 & - & - & - \\
\hline P. aeruginosa MDRPA3 & 3.75 & 3.75 & & 7.5 & 7.5 & - \\
\hline
\end{tabular}

The MIC values are showed as mean (n=3), S. flexneri: Shigella flexneri, E. faecalis: Enterococcus faecalis, S. aureus: Staphylococcus aureus, P. mirabilis: Proteus mirabilis, $S$. typhi: Salmonella typhi, S. marcescens: Serratia marcescens, P. aeruginosa: Pseudomonas aeruginosa, K. pneumoniae: Klebsiella pneumoniae, E. coli: Escherichia coli 


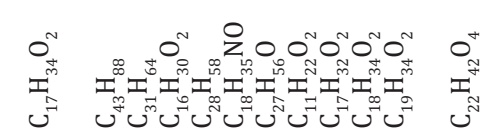

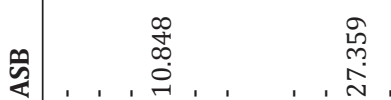

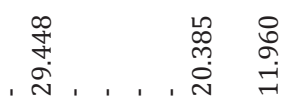



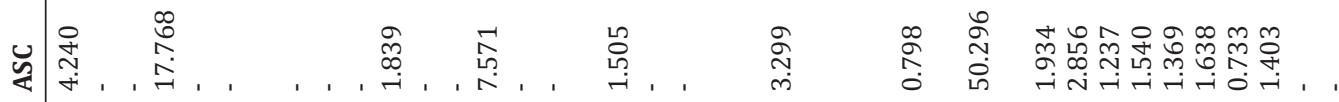

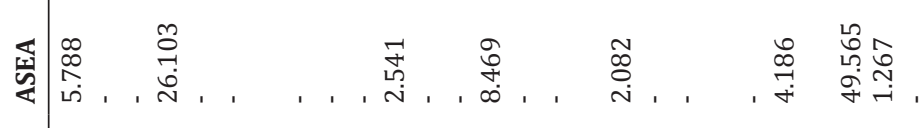

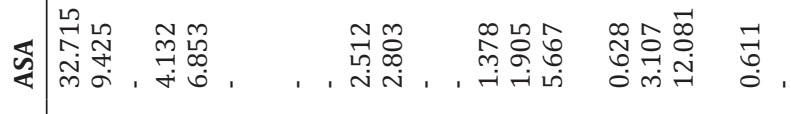


Table 5: Identified compounds of $A$. sativum and their biological activity reported in literature

\begin{tabular}{|c|c|c|}
\hline Name of the compounds & Biological activity & References \\
\hline Dodecanoic acid & $\begin{array}{l}\text { Anti-Mycobacterium tuberculosis, antibacterial, antiviral } \\
\text { and antifungal }\end{array}$ & {$[31,32]$} \\
\hline Tetradecanoic acid & Larvicidal and repellent activity & {$[33]$} \\
\hline Pentadecanoic acid & Antioxidant & {$[34]$} \\
\hline hexadecanoic acid, methyl ester 9 & Antibacterial and antifungal & {$[35]$} \\
\hline n-Hexadecanoic acid & $\begin{array}{l}\text { Anti-inflammatory, antioxidant, hypocholesterolemic } \\
\text { nematicide, pesticide, antiandrogenic flavor, hemolytic, } \\
\text { 5-alpha reductase inhibitor, potent mosquito larvicide }\end{array}$ & {$[36,37]$} \\
\hline 9-Octadecenoic acid (Z) methyl ester & Antioxidant, anticancer & {$[38]$} \\
\hline Octadecanoic acid & Antimicrobial activity & {$[37]$} \\
\hline Dodecanoic acid, methyl ester & Antibacterial, antiviral, antifungal & [39] \\
\hline Squelene & $\begin{array}{l}\text { Antibacterial, antioxidant, antitumor, cancer preventive, } \\
\text { chemopreventive, immunostimulant, lipoxygenase } \\
\text { inhibitor }\end{array}$ & [34] \\
\hline Oleic acid & $\begin{array}{l}\text { 5-Alpha-reductase-inhibitor, allergenic, } \\
\text { alpha-reductase-inhibitor, anemiagenic, antialopecic, } \\
\text { antiandrogenic, anti-inflammatory, antileukotriene, } \\
\text { cancer preventive, choleretic, dermatitigenic, } \\
\text { flavor, hypocholesterolemic, insectifuge, irritant, } \\
\text { percutaneostimulant }\end{array}$ & {$[34]$} \\
\hline
\end{tabular}

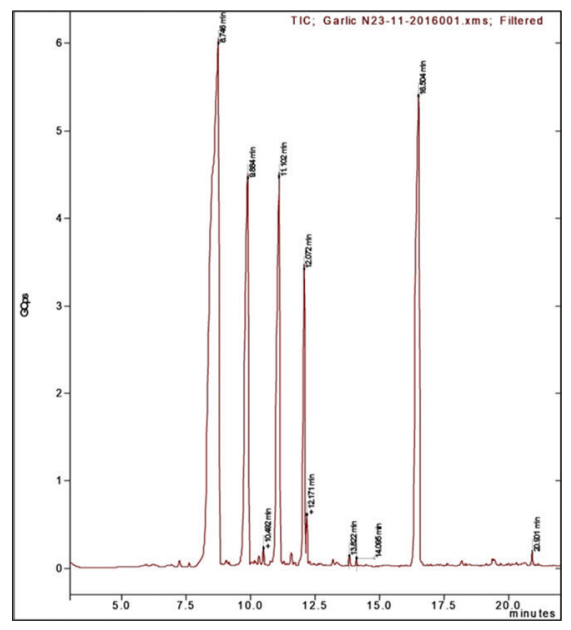

Fig. 1: Gas chromatography-mass spectrometry spectra of methanol extract

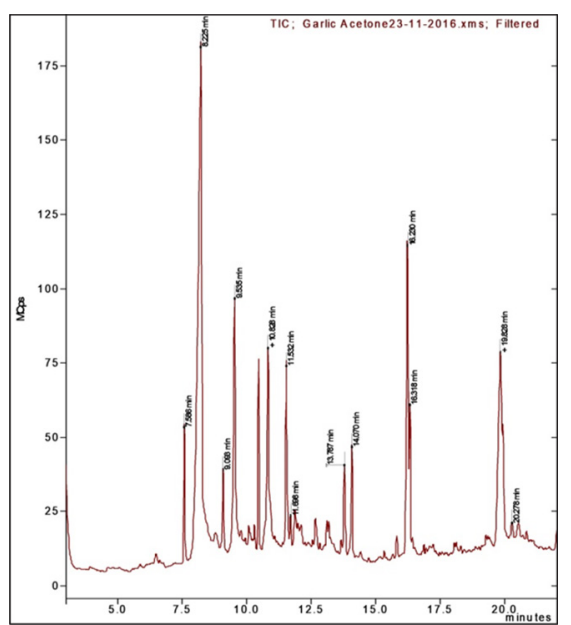

Fig. 2: Gas chromatography-mass spectrometry spectra of acetone extract

carbohydrates, alkaloids, cardiac glycosides, saponins, flavonoids, terpenes, and steroids [23-25]. Allicin, ajoene, thiosulfinates, and a wide

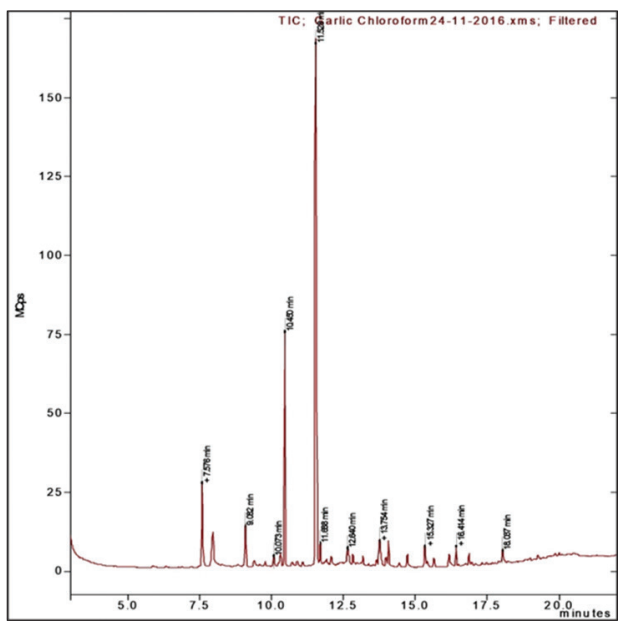

Fig. 3: Gas chromatography-mass spectrometry spectra of chloroform extract

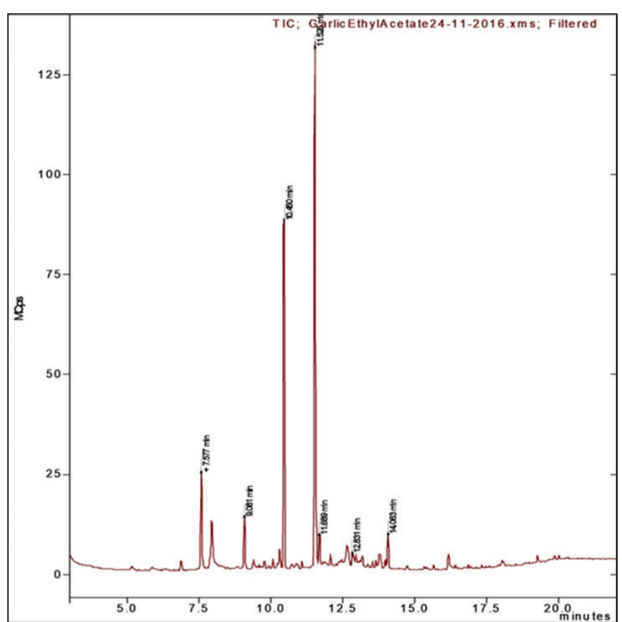

Fig. 4: Gas chromatography-mass spectrometry spectra of ethyl acetate extract

range of other organosulfurate compounds are the major constituents which are responsible for the antimicrobial activity of $A$. sativum [26]. 


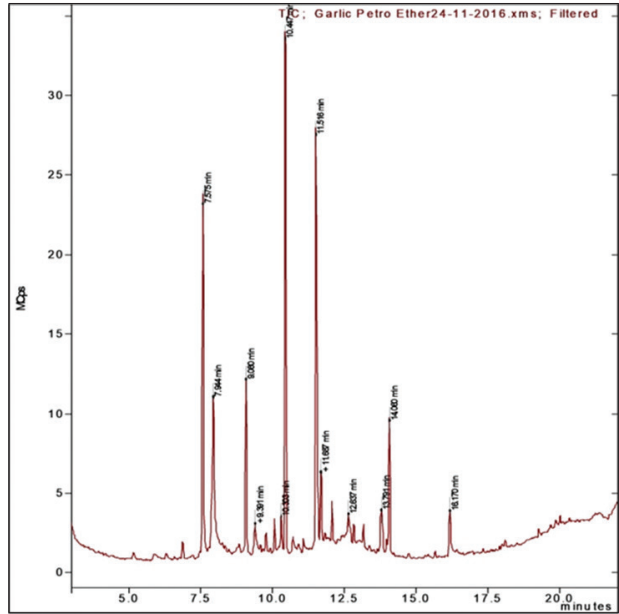

Fig. 5: Gas chromatography-mass spectrometry spectra of petroleum ether extract

The bioactive compounds of six different garlic extracts were compared through GC-MS analysis as summarized in Table 4, and a total number of 35 compounds from six different extracts were identified. In methanol extract, the \% of total of dodecanoic acid, tetradecanoic acid, n-hexadecanoic acid, and 13-docosenamide was higher than other extracts, i.e., 45.306, 14.822, 12.963, and 19.948, respectively. The dodecanoic acid and n-hexadecanoic acid have been reported previously to have antibacterial activities that may be the reason of highest antibacterial activity of methanol extract against reference strains [27].

The results showed that hexadecanoic acid and methyl ester were detected in all six extracts while two compounds, dodecanoic acid and Bis(2-ethylhexyl) phthalate were present five extracts except benzene extract. These substances are produced by the plants as secondary metabolites and may have beneficial or adverse effects [28-30]. As the benzene extract was found inactive against all the bacterial strain, we can conclude that the antibacterial activity against reference strains was due to the presence of dodecanoic acid and in case of MDR due to the presence of derivative of dodecanoic acid, i.e., dodecanoic methyl ester in acetone extract as shown in Table 4.

Some of the major identified compounds have been found to have remarkable biological activities against certain illnesses and/ or microbial pathogens as shown in Table 5 with references from literature. These compounds might be responsible for the antibacterial efficacy of the plants extract.

The acetone extract was found most active against MDR strains. The main phytoconstituents identified from acetone extract were dodecanoic acid, tetradecanoic acid, 9-octadecenamide (Z), and dodecanoic acid 1, 2, 3-propanetriyl ester. The presence of the derivative of dodecanoic acid, namely, dodecanoic acid, methyl ester, and dodecanoic acid, 1, 2, 3 -propanetriyl ester in acetone extract may be the reason of its potential against MDR strains. Some other additional compounds identified in acetone extracts were methyl tetradecanoate, 9, 12-octadecadienoyl chloride, (Z,Z), methyl stearate, squalene, and oleic acid also may be the reason for the antibacterial potential against MDR strains.

\section{CONCLUSION}

There are many scientific reports which stated that $A$. sativum has great potential for the treatment of various infectious diseases. In the present study, garlic was found to have good antibacterial activity against reference as well as MDR bacterial strains. The GCMS analysis shows the presence of bioactive compounds mainly dodecanoic acid and dodecanoic acid, methyl ester which may be responsible for the antibacterial activity of A. sativum. Thus, these compounds should be isolated and their pharmacokinetic properties and toxicity should be analyzed.

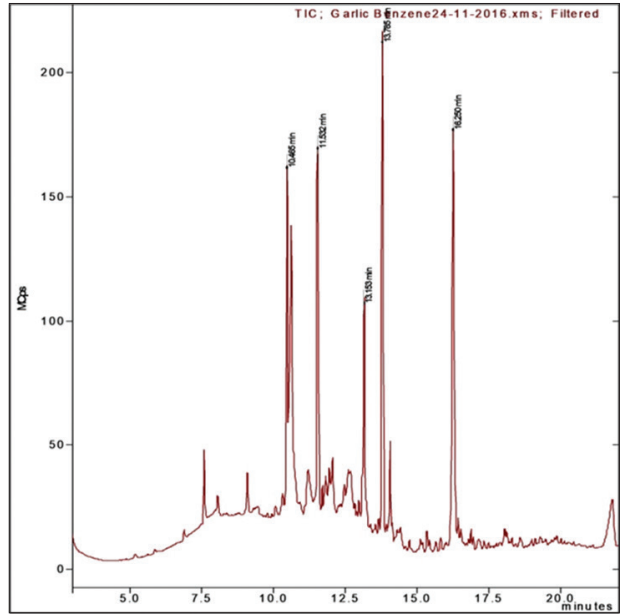

Fig. 6: Gas chromatography-mass spectrometry spectra of benzene extract

\section{ACKNOWLEDGMENT}

This research work was supported by grant from UGC, New Delhi, in form of UGC BSR [F.4-1/2006 (BSR/7-371/2012] \& UGC-SAP [F.20/2012(SAP-II)].

\section{AUTHORS CONTRIBTION}

Dushyant Sharma has performed experimentation work and data collection and drafted the manuscript. Reena Rani made significant involvement in the interpretation of data and revising the manuscript. Monika Chaturvedi participated in the design of the study and performed the statistical analysis. Jaya Parkash Yadav helped in designed the study and finalization of the manuscript.

\section{CONFLICT OF INTEREST}

There is no conflict of interest between authors.

\section{REFERENCES}

1. Sharma D, Yadav JP. An overview of phytotherapeutic approaches for the treatment of tuberculosis. Mini Rev Med Chem 2017:17:167-83.

2. Sharma V, Chaudhary U. An overview on indigenous knowledge of Achyranthes aspera. J Crit Rev 2015;2:7-19.

3. Newman DJ, Cragg GM, Snader KM. Natural products as sources of new drugs over the period 1981-2002. J Nat Prod 2003;66:1022-37.

4. Scharbert G, Kalb ML, Duris M, Marschalek C, Langenecker SA. Garlic at dietary doses does not impair platelet function. Anesth Analg 2007;105:1214-8.

5. Salie F, Eagles PF, Lens HM. Preliminary antimicrobial screening of four South African Asteraceae species. J Ethnopharmacol 1996;52:27- 33.

6. Pradeepa M, Kalidas V, Geetha N. Qualitative and quantitative phytochemical analysis and bactericidal activity of Pelargonium graveolens 1'her. Int J Appl Pharm 2016;8:7-11.

7. Douaouya LI, Bouzerna N. Effect of garlic (Allium sativum L) on biochemical parameters and histopathology of pancreas of alloxaninduced diabetic rats. Int J Pharm Pharm Sci 2016;8:202-6.

8. Abdel-Gawad MM, El-Hashash MA, El-Sayed MM, El-Wakil EA, Abdel-Lateef EE. Chromatographic isolation of Allium cepa (ssp. Red onion) and its cytotoxic activity against human liver carcinoma cell lines (hepg2). Int J Pharm Pharm Sci 2014;6:108-11.

9. Olusanmi MJ, Amadi JE. Studies on the antimicrobial properties and phytochemical screening of garlic (Allium sativum) extracts. Ethnobot Leaf 2009;2009:1186-96.

10. Tripathi K. Garlic, the spice of life-(Part-I). Asian J Res Chem 2009;2:8- 13 .

11. Divya B, Suman B, Venkataswamy M, Thyagaraju K. A study on phytochemicals, functional groups and mineral composition of Allium sativum (garlic) cloves. Int J Curr Pharm Res 2017;9:42-5.

12. Block E, Ahmad S. (E, Z)-Ajoene a potent antithrombotic agent from garlic. J Am Chem Soc 1984;106:95-6. 
13. Block E, Ahmad S, Catalfamo JL, Jain MK, Apitz-Castro R. Antithrombotic organosulfur compounds from garlic: Structural, mechanistic and synthetic studies. J Am Chem Soc 1986;108:7045-55.

14. Rani R, Sharma D, Chaturvedi M, Yadav JP. Antibacterial activity of twenty different endophytic fungi isolated from Calotropis procera and time kill assay. Clin Microbiol 2017;6:1-6.

15. Sarker SD, Nahar L, Kumarasamy Y. Microtitre plate-based antibacterial assay incorporating resazurin as an indicator of cell growth, and its application in the in vitro antibacterial screening of phytochemicals. Methods 2007;42:321-4.

16. Ross ZM, O'Gara EA, Hill DJ, Sleightholme HV, Maslin DJ. Antimicrobial properties of garlic oil against human enteric bacteria: Evaluation of methodologies and comparisons with garlic oil sulfides and garlic powder. Appl Environ Microbiol 2001;67:475-80.

17. Rees LP, Minney SF, Plummer NT, Slater JH, Skyrme DA. A quantitative assessment of the antimicrobial activity of garlic (Allium sativum). World J Microbiol Biotechnol 1993;9:303-7.

18. Weber ND, Andersen DO, North JA, Murray BK, Lawson LD, Hughes $\mathrm{BG}$, et al. In vitro virucidal effects of Allium sativum (garlic) extract and compounds. Planta Med 1992;58:417-23.

19. Aboaba OO, Efuwape BM. Antibacterial properties of some Nigerian species. Bio Res Comm 2001;13:183-8.

20. Karuppiah P, Rajaram S. Antibacterial effect of Allium sativum cloves and Zingiber officinale rhizomes against multiple-drug resistant clinical pathogens. Asian Pac J Trop Biomed 2012;2:597-601.

21. Venâncio PC, Figueroba SR, Nani BD, Ferreira LE, Muniz BV, Del Fiol FD, et al. Antimicrobial activity of two garlic species (Allium sativum and Allium tuberosum) against staphylococci infection. In vivo study in rats. Adv Pharm Bull 2017;7:115-21.

22. Rath S, Padhy RN. Monitoring in vitro antibacterial efficacy of 26 Indian spices against multidrug resistant urinary tract infecting bacteria. Int Med Res 2014;3:133-41.

23. Tiwari S, Sirohi B, Shukla A, Bigoniya P. Phytochemical screening and diuretic activity of Allium sativum steroidal and triterpenoid saponin fraction. Int J Pharm Sci Res 2012;3:3354-61

24. Huzaifa U, Labaran I, Bello AB, Olatunde A. Phytochemical screening of aqueous extract of Garlic (A. sativum) bulbs. Rep Opin 2014;6:1-4.

25. Gazuwa SY, Makanjuola ER, Jaryum KH, Kutshik JR, Mafulul SG. The phytochemical composition of Allium CepalAllium sativum and the effect of their aqueous extracts (cooked and raw forms) on the lipid profile and other hepatic biochemical parameters in female albino wistar rats. Asian J Exp Biol Sci 2013;4:406-10.

26. Ledezma E, Apitz-Castro R. Ajoene the main active compound of garlic (A. sativum): A new antifungal agent. Rev Iberoam Micol 2006;23:75- 80

27. Makkar HP, Francis G, Becker K. Bioactivity of phytochemicals in some lesser-known plants and their effects and potential applications in livestock and aquaculture production systems. Animal 2007;1:1371-91.

28. Rochfort S, Panozzo J. Phytochemicals for health, the role of pulses. J Agric Food Chem 2007;55:7981-94.

29. Abubakar MN, Runner RT. GC-MS analysis and preliminary antimicrobial activity of Albizia adianthifolia (Schumach) and Pterocarpus angolensis (DC). Medicines 2016;3:1-9.

30. Muniyan R, Gurunathan J. Lauric acid and myristic acid from Allium sativum inhibit the growth of mycobacterium tuberculosis H37Ra: In silico analysis reveals possible binding to protein kinase B. Pharm Biol 2016;54:2814-21.

31. Nitbani FO, Dwi S, Eti NS. Isolation and antibacterial activity test of lauric acid from crude coconut oil (Cocos nucifera L.). Proc Chem 2016;18:132-40.

32. Sivakumar R, Jebanesan A, Govindarajan M, Rajasekar P. Larvicidal and repellent activity of tetradecanoic acid against Aedes aegypti (Linn.) and Culex quinquefasciatus (Say.) (Diptera: Culicidae). Asian Pac J Trop Med 2011;4:706-10

33. Duke JA. Dr Duke's Phytochemical and Ethnobotanical Database. Phytochemical Database. Beltsville, Meryland: USDA-ARS-NGRL, Beltsville Agricultural Research Center; 1992.

34. Chandrasekaran M, Senthilkumar A, Venkatesalu V. Antibacterial and antifungal efficacy of fatty acid methyl esters from the leaves of Sesuvium portulacastrum L. Eur Rev Med Pharmacol Sci 2011;15:775- 80.

35. Aparna V, Dileep KV, Mandal PK, Karthe P, Sadasivan C, Haridas M, et al. Anti-inflammatory property of n-hexadecanoic acid: Structural evidence and kinetic assessment. Chem Biol Drug Des 2012:80:434-9.

36. Kumar P, Praveen S, Kumar A, Lalitha C. Screening of antioxidant activity, total phenolics and GC-MS study of Vitex negundo. Afr J Biochem Res 2010;4:191-5.

37. Rahuman AA, Gopalakrishnan G, Ghouse BS, Arumugam S, Himalayan B. Effect of Feronia Limonia on mosquito larvae. Fitoterapia 2000;71:553-5.

38. Asghar SF, Choudahry MI. Gas chromatography-mass spectrometry (GC-MS) analysis of petroleum ether extract (oil) and bio-assays of crude extract of Iris germanica. Int J Gen Mol Bio 2011;3:95-100.

39. Ozçelik B, Aslan M, Orhan I, Karaoglu T. Antibacterial, antifungal, and antiviral activities of the lipophylic extracts of Pistacia vera. Microbiol Res 2005;160:159-64. 